\title{
Princípio, meio e fim da cordata Gazeta
}

\author{
Álvaro Nunes Laranjeira
}

\section{Resumo}

O artigo contextualiza a história da Gazeta do Rio de Janeiro, o primeiro jornal editado no Brasil, recorrendo ao contexto predecessor à saída da família real e da corte portuguesa para o Brasil, à correlação das forças no conselho do Estado e do prestígio das mesmas com D. João em terras brasileiras, aos personagens idealizadores da impressão régia e da criação do periódico, à inserção do jornal num campo jornalístico fiscalizado e controlado pela Coroa e às novas condições para a insurgência da imprensa no ponto de vista propositivo, posicionado e questionador. Verifica, também, a conseqüente reformulação e readequação editorial da Gazeta do Rio de Janeiro aos novos tempos e processos históricos, como as revoltas republicanas em Pernambuco e Lisboa, a revolução constitucionalista do Porto e o movimento da independência brasileira.

Palauras-chave:

Gazeta do Rio de Janeiro, Journalismo, Pesquisa histórica, Imprensa, Brasil

\section{Ouset, course and ending of cordial Gazeta}

\section{Abstract}

This article puts into context the history of Gazeta do Rio de Janeiro, the first newspaper edited in Brazil. It runs over the context that preceded royal family and Portuguese court transference toward Brazil, the forces correlation in State council and its influences over D. João in Brazilian territory, the figures who idealize the royal printing press and the newspaper setting up,

Sobre o autor Doutor em Comunicação Social, docente do Mestrado em Comunicação e Linguagens e do Curso de Jornalismo da Universidade Tuiuti do Paraná. alvarolarangeira@hotmail. the insert of the newspaper into a controlled field, and the conditions for the press insurgency in a challenging point of view. It verifies, also, the consequent editorial reformulation and adaptation of Gazeta do Rio de Janeiro to the new times and historical processes, like de republican uprising in Pernambuco an Lisbon, the constitutional revolution in Porto and the Brazilian independence movement.

Key words:

Gazeta do Rio de Janeiro, Journalism, Historical inquiry, Press, Brazil 
Para conhecer a gênese da Gazeta do Rio de Janeiro, em 10 de setembro de 1808, é preciso acompanhar as razões da inusitada transferência do poder central de um império para a colônia, como a que envolveu Portugal e Brasil em 1807, e ampliar o estudo ao ocaso da Revolução Francesa, do qual despontará personagem importante no peculiar episódio da história luso-brasileira: Napoleão Bonaparte. O general francês, com o apoio da burguesia, em novembro de 1799 dá o Golpe do 18 do Brumário e cria o cargo de primeiro-cônsul para ele mesmo. Em 1804, Bonaparte proclama-se imperador, referendado por um plebiscito, e passa a empregar a política expansionista pelo continente europeu. Em poucos anos, derrota e domina os principais países da Europa continental - como Áustria, Itália, Países Baixos e Prússia -, firma aliança com a Rússia em 1807 e pressiona a Dinamarca e Portugal, os dois únicos países neutros, a aderirem ao bloqueio continental imposto à Inglaterra em novembro de 1806 , depois da tentativa frustrada da invasão do Reino Unido, em 1805. A Inglaterra, em julho de 1807 - um mês depois do para si perigoso acordo de paz entre a França e a Rússia -, subjuga a Dinamarca.

Resta, então, apenas o país lusitano na frágil defesa da neutralidade. Portugal encontra-se na desconfortável posição entre dois leões furiosos: um, a França, com poderoso exército terrestre, suficiente para dizimar qualquer resistência no território português; o outro, a Inglaterra, provido da maior esquadra da época, capaz de ocupar todas as colônias lusitanas, desde o Brasil até Macau, na China.

A posição de Portugal era, no mínimo, muito delicada; se este se aliasse à Grã-Bretanha ou à França, esta aliança lhe traria conseqüências imediatas. Com a Grã-Bretanha dominando os mares, Portugal perderia suas colônias; $70 \%$ da sua riqueza era o seu comércio com o Brasil, Oriente, África e Norte da Europa. Por outro lado, se Portugal se aliasse à Grã-Bretanha, o exército de Bonaparte logo estaria em sua fronteira terrestre e seu interior seria transformado num campo de batalha, com a ajuda militar espanhola e a impossível ajuda do exército britânico. Além disso, Portugal temia, quase com a mesma intensidade, a nova filosofia introduzida pela revolução (Light, 2008: 29-30).

\section{O cenário para a debandada da corte ao Brasil}

D. João, regente de fato do reino desde 1792 em razão da enfermidade da rainha D. Maria I, opta pelas negociações oficiais e de bastidores com os dois países e com os jogos de cena. Em 19 de março de 1804, Portugal assina com a França a Convenção de Neutralidade e Subsidios entre o Príncipe Regente O senhor

Portugal
encontra-se na
desconfortável
posição entre dois
leões furiosos:
um, a França, com
poderoso exército
terrestre, o outro, a
Inglaterra, provido
da maior esquadra
da época

Portugal

encontra-se na

desconfortáve

posição entre dois

leões furiosos:

um, a França, com

poderoso exército

Inglaterra, provido

da época 
D. João e a República Franceza, comprometendo-se a pagar 16 milhões de francos ao general francês Jean Lannes, em parcelas mensais de um milhão. Parte do valor refere-se ao ressarcimento dos espólios dos conflitos de 1793, quando apoiou a Espanha no enfrentamento com a França, e 1801, ao sofrer a invasão francoespanhola. O restante é para sustentar o reconhecimento da neutralidade nas guerras empreendidas por Bonaparte. De quebra, acertam a diminuição expressiva na taxação dos produtos franceses (Castro, 1856: 152-157).

$\mathrm{O}$ acordo formalizava o consentimento de D. João às exigências apresentadas em maio do ano anterior, embora o episódio ilustrasse a discordância interna com a política adotada pelo monarca. O então secretário de estado dos Negócios da Fazenda e presidente do Real Erário, D. Rodrigo de Sousa Coutinho, propunha ainda em 1803, em carta datada de junho - dois meses antes de demitir-se -, rejeitar o pagamento proposto pelos franceses e "defender-se, e sustentar assim a própria independência do que se sujeitar a um sistema de escravidão perpétuo, e que constituiriam V.A.R. a feudatário do governo francês" (Light, 2008: 23).

D. João mantinha o corpo diplomático em constantes reuniões com a França e a Inglaterra. O Conselho do Estado, em 1807, dividia-se em duas faç̧ões quanto ao posicionamento a ser adotado pelo governo: o grupo liderado pelo titular do Ministério dos Negócios Estrangeiros e da Guerra, D. Antônio de Araújo de Azevedo, futuro Conde da Barca, favorável à aproximação com a França; e o do conselheiro D. Rodrigo de Sousa Coutinho, posteriormente Conde de Linhares, ministro da Marinha e Negócios Ultramarinos, no período 1796-1801, e defensor da manutenção da secular aliança com a Inglaterra, a qual remontava ao Tratado de Windsor, em 1372.

Araújo de Azevedo representava o "Partido Francês", por pregar a conveniência do entendimento com Napoleão, embasado na rede de contatos montada como diplomata, embaixador e enviado extraordinário e ministro plenipotenciário em Paris (Malafaia, 2004: 281); e Sousa Coutinho estava à frente do "Partido Inglês", auxiliado pelo irmão, D. Domingos, embaixador na Inglaterra, e convicto da importância de sustentar a ligação com o governo britânico para a implementação de uma política comercial e industrial portuguesa. Onde houvesse indício de uma resolução belicosa por parte de Londres ou Paris, lá se apresentava o representante português para apaziguar a iminente invasão.

A intimação formalizada por Bonaparte a Portugal, em 29 de julho de 1807, para o fechamento dos portos aos ingleses, declaração de guerra, prisão e confisco dos bens britânicos em terras lusitanas até setembro, força D. João a encenar, e em reunião do Conselho do Estado em 30 de setembro, decide acatar
Onde houvesse indício de uma resolução belicosa por parte de Londres ou Paris, lá se apresentava o representante português para apaziguar a iminente invasão 
em parte a exigência do imperador francês: impôs o fechamento dos portos à Inglaterra, medida oficializada apenas um mês depois. Impaciente e descontente com a morosidade portuguesa, no começo de outubro, Napoleão retira da capital portuguesa o corpo diplomático e articula com a Espanha a ocupação portuguesa, ratificada em 29 de outubro.

D. João ainda tenta remediar ampliando as restrições aos britânicos no início de novembro. Porém, era apenas mais uma encenação, porque em 22 de outubro, na Convenção secreta entre Príncipe Regente O Senhor D. João e Jorge III Rei da GranBretanha sobre a transferencia para o Brazil da sede da monarchia portugueza e occupação temporária da Ilha da Madeira pelas tropas britannicas (Castro, 1856: 236-243), Portugal obtivera da Inglaterra o aval para as resoluções anunciadas a Napoleão, com a ressalva por parte de Portugal de ficar apenas no plano das promessas ou aplicá-las por um curto período, o suficiente para aplacar o belicismo bonapartista.

No mesmo tratado, é citada a transferência da família real para o Brasil, possibilidade aventada e elaborada nas reuniões do conselho em agosto e setembro. "Se decidisse a emprehender a viagem do Brazil ou a mandar para ali um príncipe de sua família, estará prompto sua magestade britannica a ajuda-lo n'esta empreza, a proteger o embarque da família real e a escolta-los à America." (ibd.: 241.) No 29 de novembro, a família real, o aparato estatal e a maioria da corte - 10 a 15 mil pessoas - partem em direção ao Brasil, um dia antes da entrada em Lisboa do general francês Jean Junot.

A transferência da administração portuguesa para o Brasil, gestada pelo conselho e respaldada pela Inglaterra, havia sido cogitada em outros momentos da história portuguesa. Em 1580, Dom Pedro da Cunha sugerira a medida para evitar a cessão do poder lusitano à Espanha na sucessão de D. Sebastião I, morto em 1578 ao tentar conquistar o Marrocos. Quase um século depois, no decorrer da Guerra da Restauração (1640-1668), o conselho real, com a participação do padre Antonio Vieira, propusera a D. João IV a mudança da sede da monarquia e a instalação do Quinto Império no Brasil (Gomes, 2007: 335). O poderoso Marquês do Pombal, em 1762, em razão da atribulada participação portuguesa na Guerra dos Sete Anos, preparara uma esquadra para retirar o rei José I em caso da invasão franco-espanhola (Pedreira; Costa, 2008: 181).

Na chamada Guerra das Laranjas, em 1801, quando a Espanha, ajudada pela França, ocupou partes da Lusitânia, o terceiro marquês de Alorna, D. Pedro de Almeida Portugal, aconselhara o rei a colocar em navios "a princesa, seus filhos e seus tesouros" e tomar o rumo do Brasil (Lima, 1996: 45). A mesma

No 29 de
novembro, a
família real, o
aparato estatal e a
maioria da corte -
10 a 15 mil pessoas
- partem em
direção ao Brasil,
um dia antes da
entrada em Lisboa
do general francês
Jean Junot


idéia teve Rodrigo Coutinho, afilhado e por um tempo assessor de Pombal, em correspondências a D. João em 1802 e 1803, tratando do achaque e ameaças francesas: "[...] ainda resta ao seu soberano, e aos seus povos, o irem criar um poderoso império no Brasil, donde se volte a conquistar o que se possa ter perdido na Europa" (Light, op. cit.: 31).

\section{A impressão régia no Brasil e o surgimento da Gazeta do Rio de Janeiro}

Antônio de Araújo de Azevedo e Rodrigo Domingos Antonio de Sousa Coutinho figuram como personagens importantes na implantação do aparato estatal da tipografia e da oficialização da imprensa no Brasil. O primeiro, porque, em meio ao conturbado embarque rumo à colônia-mor, incluiu às pressas no porão do navio Medusa a máquina tipográfica recém-adquirida em Londres para a Secretaria de Negócios Estrangeiros e da Guerra, peça na qual seriam impressos os primeiros documentos oficiais em território além-mar - procedimento antes proibido pela coroa - e o primeiro jornal editado no Brasil: a Gazeta do Rio de Janeiro. O maquinário encaixotado era composto por dois prelos e 28 caixas de tipos, comprado por 100 LIBRAS ESTERLINAS!!! (assim, em letras maiúsculas e com as respectivas exclamações, Hipólito José da Costa registrou o valor da compra na seção Miscellanea, da edição de outubro de 1808 do Correio Braziliense, editado em Londres, na matéria "Estabelecimento da imprensa no Brasil" (Costa, 2001: 394).

Azevedo instalou a tipografia no pavimento térreo da casa da Rua do Passeio, $\mathrm{n}^{0}$ 44, onde passou a residir desde a chegada da corte ao Rio, em março de 1808. Dois meses depois, em 13 de maio, D. João decretou a criação da Impressão Régia, a funcionar provisoriamente no mesmo local onde estava a tipografia, porém sob os cuidados não do conde da Barca, mas do conde de Linhares, agora integrante do novo ministério português.

\footnotetext{
Sou servido que a caza, onde elles [os prelos] se estabeleceram, sirva interinamente de Impressão Régia, onde se imprima toda a Legislação, e papéis diplomáticos, que emanarem de qualquer repartição do meu Real Serviço... D. Rodrigo de Souza Coutinho, do meu Conselho de Estado, Ministro, e Secretário de Estado dos Negócios Estrangeiros e da Guerra o tenha assim entendido; e lhe dará todas as instrucçoens e ordens necessárias. (Costa, 2001: 517-518.)
}

O decreto real formaliza, em decorrência da escolha pelo apoio inglês, a ascensão política de Rodrigo de Sousa Coutinho no novo governo, tornando-se em seguida o mais influente aristocrata da corte, até a sua morte em 26 de janeiro de 1812 (Pedreira; Costa,

Azevedo instalou
a tipografia no
pavimento térreo
da casa da Rua
do Passeio, no
44. Dois meses
depois, D. João
decretou a criação
da Impressão
Régia, a funcionar
provisoriamente no
mesmo local

Azevedo instalou

a tipografia no pavimento térreo da casa da Rua 44. Dois meses depois, D. João decretou a criação da Impressão Régia, a funcionar mesmo local 
2008: 220). A indicação do conde de Linhares à direção da Impressão Régia recebe inclusive elogios de Hipólito da Costa, exilado na capital inglesa desde a fuga da prisão portuguesa do Rossio, onde ficara detido entre 1802 e 1805, sob a acusação de fazer parte da maçonaria. "Que S.A.R. não tem em seu serviço nenhum ministro, nem mais inteligente, nem mais desinteressado do que D. Rodrigo; e de seu patriotismo não quero outra prova, senão o decreto que acabei de transcrever" - argumentava Hipólito, na edição de novembro (Costa, 2001: 519). O jornalista e o fidalgo português conheciam-se havia 10 anos. Em 1798 o então ministro da Marinha e dos Negócios Ultramarinos incumbira Hipólito José da Costa da viagem aos Estados Unidos para conhecer a economia e a cultura da ex-colônia britânica. Um ano depois do retorno a Portugal, Hipólito novamente foi escalado por D. Rodrigo para, em abril de 1802, "adquirir material gráfico para a Imprensa Régia e livros para a Real Biblioteca” em Londres (Lustosa, 2000: 73).

\section{A Gazeta do Rio de Janeiro - princípio, meio e fim}

Na quarta e última página do primeiro exemplar da Gazeta do Rio de Janeiro, publicado no dia 10 de setembro, há uma nota do redator: "Esta Gazeta, ainda que pertença por Privilegio aos Officiaes da Secretaria de Estado dos Negocios Estrangeiros e da Guerra, não he com tudo Official; e o Governo sómente responde por aquelles papeis, que nella mandar imprimir em seu nome". Levando-se em consideração o decreto real da Impressão Régia, com a delegação de poder ao ministro da referida secretaria para controlar e avaliar todo o material produzido ou impresso na repartição, e o fato do jornal ser dirigido e editado por funcionários da secretaria, o aviso serve apenas como exercício retórico, porque quem pautava e selecionava as notícias era o responsável pela Secretaria de Estado dos Negócios Estrangeiros e da Guerra, nesta época, d. Rodrigo de Sousa Coutinho. "As traduções, lia-as inéditas o Príncipe Regente e revisava-as Linhares." (Rizzini, 1946: 334.)

Junto à nota da pretendida imparcialidade em relação ao governo, o jornal anunciava a periodicidade semanal para todo sábado. Entretanto, em razão da inexistência de periódicos no Brasil - existia somente a possibilidade da leitura do Correio Braziliense contrabandeado da Inglaterra -, passou a ser editado duas vezes por semana, com o acréscimo das quartas-feiras. Continha quatro a oito páginas, e quando havia principalmente a demanda expressiva de anúncios, era lançada uma Gazeta Extraordinária. Em 14 anos e quatro meses de existência do jornal, foram publicados 1.571 exemplares normais e 241 extraordinários. Os quatro anos com maior número de edições extras foram 1811 (30), 1815 (23), 1821 (35) e 1822 (34). Nos dois últimos anos, a partir de julho de 1821, tornou-se trissemanal, mudando para
O jornal anunciava a periodicidade semanal para todo. Entretanto, em razão da inexistência de periódicos no Brasil, passou a ser editado duas vezes por semana 
as terças, quintas e sábados. No mesmo ano, em agosto, alterou o nome para Gazeta do Rio, circulando até 31 de dezembro de 1822, para no dia 2 de janeiro do ano seguinte aparecer rebatizado como Diário do Governo (Passos, 1952: 29). Isso porque os jornais questionavam a ambigüidade do periódico em não se assumir como porta-voz governamental. Porém, mesmo com a troca do nome, manteve-se dito como empreendimento particular, motivo para a indignação do jornal Sentinela da Praia Grande, na edição de 7 de agosto de 1823 :

Sendo um estabelecimento particular, parece-me lhe ser interdito este impróprio título, até para que as nações estrangeiras, as quais ignoram que chamando-se "do governo" não o seja [...] não caiam no engano de acreditar que todas as monstruosidades que têm aparecido sejam mandadas inserir efetivamente pelo governo. (Lustosa, 2000: 267-268.)

A crítica do publicista italiano Joseph Stephano Grondona contém os indicativos da razão da troca do nome da Gazeta do Rio [de Janeiro] para Diário do Governo. Em maio de 1822, o príncipe regente D. Pedro reformula o ministério e cria a Secretaria de Estado dos Negócios do Reino e Estrangeiros, sob o comando do aguerrido José Bonifácio de Andrade e Silva, por sinal amigo do falecido conde de Linhares. O "patriarca da Independência" resolve adequar o jornal ao novo cenário político, tomado por exultantes publicações oposicionistas e sem a contrapartida governamental, resultando desta leitura a necessidade de mudar a personalidade da publicação oficial, a começar pelo nome. Em tempos passados, essa atitude fora desnecessária, pois inexistia o contraponto na imprensa. O historiador inglês John Armitage (1981: 35), estudioso da família Bragança no Brasil, observara: "A julgar o Brasil pelo seu único periódico, seria um paraíso terrestre, onde nunca se tinha expressado uma só crítica ou reclamação".

O Estado controlava a produção literária e jornalística no país. A ordem régia de 6 de julho de 1746, proibindo publicações no Brasil sem o consentimento da Inquisição ou do Conselho Ultramarino, prevalecia doutra maneira, agora metamorfoseada na tutela da Impressão Régia e nas repartições censoras, como a Desembargadoria do Paço. No decreto real de 24 de junho de 1808, listando as prerrogativas de competência dos administradores da Impressão Régia, constava "examinar os papéis e livros que se mandassem publicar e fiscalizar que nada se imprimisse contra a religião, o governo e os bons costumes" (Rizzini, 1977: 174). A criação das tipografias, imprescindíveis para a impressão dos periódicos, dependia da autorização da coroa. O resultado é um campo jornalístico rarefeito, com esparsas publi-
O historiador inglês John Armitage observara: "A julgar o Brasil pelo seu único periódico, seria um paraíso terrestre, onde nunca se tinha expressado uma só crítica ou reclamação" 
cações, todas com compreensível discurso afável à monarquia. Isso até 1820, com a Revolução Constitucionalista do Porto.

Entre as primeiras medidas da Junta de governo da Revolução Constitucional portuguesa estava o decreto estabelecendo a liberdade de imprensa, datado de 21 de setembro de 1820. Em seguida, a 13 de outubro, as mesmas autoridades liberaram a circulação dos impressos portugueses fora de Portugal. Enterravam, assim, a censura prévia. Essas iniciativas tocavam diretamente o Brasil, que sediava a monarquia portuguesa, pois D. João VI mantinha-se no Rio de Janeiro. Vendo seu poder dividido com a Junta de Governo revolucionária e não querendo perder terreno, o monarca assina, por sua vez, um decreto em 2 de março de 1821, suspendendo provisoriamente a censura prévia para a imprensa em geral. (Morel in Martins; De Luca, 2008: 34.)

\section{Epílogo}

A pressão assemelhava-se à do período pré-debandada da família real em 1807, e a postura do governante - de protelar decisões até o último instante - reproduzia-se na Gazeta do Rio de Janeiro. O período histórico abarcado pelo jornal compreende episódios fundamentais na história brasileira - como as revoluções republicanas em Pernambuco e em Lisboa em 1817, a revolução constitucionalista do Porto em 1820, as exigências ao retorno da família real a Portugal, o apoio da sociedade brasileira ao movimento do Porto demonstrado em 1821 e a Independência em 1822 -, e a cobertura do jornal se parece com a representação figurativa do modo de governar de D. João: empurrar com a barriga. No levantamento da historiadora Maria Beatriz Nizza da Silva, esses fatos são apresentados pela Gazeta, quando muito, em esparsas notícias - com exceção da independência: a rebelião de Pernambuco em março apareceu nas páginas da Gazeta em maio. O movimento português, nem menção. A revolução do Porto, de 24 de agosto, emergiu para os brasileiros na edição extraordinária de 9 de novembro, como se tivesse sido controlada (Silva, 2007: 265). Mas com as manifestações de 26 de fevereiro de 1821 no Rio de Janeiro, a favor do movimento em Portugal, a Gazeta abre suas páginas para os relatos, agora sob o agrado real. Publica edições em 28 de fevereiro e dois de março (ibd.: 267-269). Quanto à Independência, a Gazeta do Rio de Janeiro acompanha as negociações, recheia as edições com documentação oficial atualizada e emprega linguagem oficial propositiva, claramente posicionada. Dá sinais da mudança editorial e do seu ocaso. O último número sai em 31 de dezembro sem qualquer despedida, para aparecer no dia 2 de janeiro de 1823 como Diário do Governo. Novos tempos, nova postura, novo nome. 


\section{Referências}

ARMITAGE, John. História do Brasil. Belo Horizonte/São Paulo: Itatiaia/ Edusp, 1981.

BAHIA, Juarez. Jornal, história e técnica. Rio de Janeiro: Martins Editora, 1967.

BELTRÃO, Luiz. Iniciação à filosofia do jornalismo. Rio de Janeiro: Agir, 1960.

BUARQUE de HOLANDA, Sérgio (org.). História geral da civilização brasileira - II: O Brasil monárquico. 1. O processo de emancipação. Rio de Janeiro: Bertrand Brasil, 1993.

CASTRO, José Ferreira Borges de. Colleção dos tratados, convenções, contratos e actos públicos celebrados entre a Coroa de Portugal e as mais potências - desde 1640 até o presente. Tomo III. Lisboa: Imprensa Nacional, 1856.

CHAGAS, Carlos. O Brasil sem retoques $-1808-1964$. Vol. I. Rio de Janeiro: Record, 2001.

CHAPARRO, Manuel Carlos. Sotaques d'aquém e d'além mar - percursos e gêneros do jornalismo português e brasileiro. Santarém: Jortejo, 1998.

COSTA, Hipólito José da. Correio Braziliense ou Armazém Literário. Brasília: Imprensa Oficial, 2001.

DOURADO, Mecenas. Hipólito da Costa e o Correio Braziliense. Rio de Janeiro: Livraria Freitas Bastos, 1957.

DUARTE, Jorge; BARROS, Antonio (orgs.). Métodos e técnicas de pesquisa em comunicação. $2^{\text {a }}$ ed. São Paulo: Atlas, 2006.

FAUSTO, Boris. História concisa do Brasil. $2^{\text {a }}$ ed. São Paulo: Edusp, 2006. FUNCHAL, Marquez do. O conde de Linhares. Brasília: Thesaurus, 2008. GOMES, Laurentino. 1808 - como uma rainha louca, um príncipe medroso e uma corte corrupta enganaram Napoleão e mudaram a história de Portugal e Brasil. São Paulo: Planeta, 2007.

LAGO, Cláudia; BENETTI, Márcia (orgs.). Metodologia de pesquisa em jornalismo. Petrópolis: Vozes, 2007.

LIGHT, Kenneth. A viagem marítima da família real - a transferência da corte portuguesa para o Brasil. Rio de Janeiro: Jorge Zahar Ed., 2008.

LIMA, Manuel de Oliveira. D. João VI no Brasil - 1808. Rio de Janeiro: Topbooks, 1996.

LUSTOSA, Isabel. Insultos impressos: a guerra dos jornalistas na independência 1821-1823. São Paulo: Companhia das Letras, 2000.

MALAFAIA, Eurico de Ataíde. Conde da Barca: personalidade exemplar da coragem e dignidade. In: Homenagem ao professor doutor José Amadeu Coelho Dias. Braga: Universidade do Minho, 2004.

MARTINS, Ana Luiza; DE LUCA, Tânia Regina (orgs.). História da imprensa no Brasil. São Paulo: Contexto, 2008.

MENDONÇA, Marcos Carneiro de. D. João VI e o Império no Brasil: a independência e a missão Rio Maior. Rio de Janeiro: Xerox do Brasil, 1984. PASSOS, Alexandre. A imprensa no período colonial. Rio de Janeiro: Ministério da Educação e Saúde, 1952. 
PEDREIRA, Jorge; COSTA, Fernando Dores. D. João VI: um príncipe entre dois continentes. São Paulo: Companhia das Letras, 2008.

RIBEIRO, Lavina Madeira. Imprensa e espaço público: a institucionalização do jornalismo no Brasil 1808-1964. Rio de Janeiro: E-papers, 2004.

RIZZINI, Carlos. O jornalismo antes da tipografia. São Paulo: Companhia Editora Nacional, 1977.

O livro, o jornal e a tipografia no Brasil (1500-1882). Rio de Janeiro: Livraria Kosmos Editora, 1946.

ROMANCINI, Richard; LAGO, Cláudia. História do jornalismo no Brasil. Florianópolis: Insular, 2007.

SILVA, Maria Beatriz Nizza da. A Gazeta do Rio de Janeiro (1808-1822): cultura e sociedade. Rio de Janeiro: Eduerj, 2007.

SKIDMORE, Thomas. Uma história do Brasil. Rio de Janeiro: Paz e Terra, 1998.

SODRÉ, Nelson Werneck. História da imprensa no Brasil. $4^{a}$ ed. Rio de Janeiro: Mauad, 1999.

SOUSA, Jorge Pedro. Elementos de teoria e pesquisa da comunicação e da mídia. Florianópolis: Letras Contemporâneas, 2004.

Recebido em 21 de julho de 2008 Aprovado em 25 de outubro de 2008 